\title{
EXPLORANDO O TRABALHO EM EQUIPE NUM CURSO DE EXTENSÃO
}

\author{
Adriano Edo Neuenfeldt ${ }^{1}$ \\ ORCID: 0000-0001-5043-1800
}

Rogério José SCHUCK ${ }^{2}$

ORCID: 0000-0001-9275-9193

\author{
Ariane Wollenhoupt da Luz Rodrigues ${ }^{3}$ \\ ORCID: 0000-0001-6977-2955 \\ Derli Juliano NeuenfeldT ${ }^{4}$ \\ ORCID: 0000-0002-1875-7226 \\ RoMÁRIO KILIAN ${ }^{5}$ \\ ORCID: 0000-0002-1609-3980
}

Resumo: Este trabalho é um recorte de um curso de extensão desenvolvido por uma instituição de Ensino Superior do Vale do Taquari-RS para pessoas com necessidades educacionais especiais. O estudo teve como objetivo desenvolver o senso de equipe a partir de atividades matemáticas organizadas de acordo com um eixo organizador. A proposta se configurou como uma pesquisa-ação, na qual aprendizes e professor da turma estabeleceram um processo

1 Doutorando em Ensino (UNIVATES - Lajeado/RS/Brasil.). Mestre em Educação (UFSM). Especialização em Tecnologias da Informação e da Comunicação Aplicadas à Educação (UFSM). Licenciatura Plena em Matemática (UFSM). Bacharelado em Desenho e Plástica (UFSM). adrianoneuenfeldt@universo.univates.br | Cel: 5599685652 | Endereço: Rua Amazonas, 92. Bairro Lorenzi, Santa Maria-RS.

2 Doutor em Filosofia (PUCRS). Professor Titular junto ao PPGEensino e PPGECE/UNIVATES/RS/BRA

3 Mestre em Ciências Sociais (UFSM/RS) Empresa Brasileira de Serviços Hospitalares, Filial Hospital Universitário de Santa Maria-RS. arianedaluzrodrigues@yahoo.com.br

4 Doutor em Ciências: Ambiente e Desenvolvimento, (UNIVATES/RS). Lajeado-RS-Brasil. derlijul@univates.br

5 Professor do Curso Técnico em Edificações na Escola Estadual de Educação Profissional Estrela - RS 
dialógico, a partir de uma mediação pedagógica. Destaca-se que para o desenvolvimento do trabalho foi necessário explorar alguns pontos, a saber: a concepção de eixo organizador; oficinas pedagógicas; a interdisciplinaridade e a mediação pedagógica. Ao final, explorando o processo de ensino e de aprendizagem, percebeu-se que as atividades proporcionaram reflexões acerca do papel dos aprendizes diante de suas próprias capacidades físicas e cognitivas; do papel diante de seus colegas; e, também, do papel que exerceriam na sociedade.

Palavras-chave: Extensão; Ensino e Aprendizagem; Necessidades Educacionais Especiais; Mediação Pedagógica; Matemática.

Abstract: This paper is a cross-section of an extension course developed by a Taquari Valley Higher Education Institution for people with special educational needs. The study aimed to develop a sense of ability to start from an organizing project. The proposal was configured as an action research, in which it was learned and the classroom teacher is a dialogical process, based on pedagogical mediation. It is emphasized that for the development of the knowledge is following some points, a saber: the Design of the organizing axis; pedagogical offices; an interdisciplinarity and pedagogical mediation. In the end, by exploring the process of teaching and learning, the activities provided reflections on the role of learners facing their physical and cognitive abilities; of paper in front of his colleagues; and also of the role they would play in society.

Keywords: Extension; Teaching and learning; Special Educational Needs; Pedagogical Mediation; Mathematics.

Resumen: Este trabajo es un recorte de un curso de extensión desarrollado por una institución de enseñanza superior del Valle del Taquari-RS para personas con necesidades educativas especiales. El estudio tuvo el objetivo de desarrollar un sentido de capacidad de partir de un proyecto organizador. La propuesta se configuró como una investigación-acción, en la que se aprendió y el profesor de la clase es un proceso dialógico, a partir de una mediación pedagógica. Se destaca que para el desarrollo del conocimiento está a continuación algunos puntos, un sable: a Diseño del eje organizador; talleres pedagógicos; una interdisciplinariedad y una mediación pedagógica. Al final, explorando el proceso de enseñanza y aprendizaje, las actividades proporcionaron reflexiones sobre el papel de los aprendices con que se enfrentan a sus habilidades físicas y cognitivas; del papel delante de sus colegas; $y$, también, del papel que ejercer en la sociedad.

Palabras clave: Extensión; Enseñanza y Aprendizaje; Necesidades Educativas Especiale; Mediación Pedagógica; Matemáticas.

Submetido em: 01/05/2019.

Aceito em: 14/05/2019. 


\section{INTRODUÇÃO}

O presente estudo teve sua gênese a partir da preocupação com o impacto de atividades matemáticas desenvolvidas por um professor da área das Ciências Exatas com um grupo de aprendizes com necessidades educacionais especiais que realizaram um curso de extensão em uma instituição superior. Essa preocupação levou à busca de estratégias de ensino para tentar resolver especificamente o seguinte problema: como desenvolver o senso de trabalho em equipe considerando as necessidades e as potencialidades individuais e do grupo de aprendizes?

Após algumas semanas observando o grupo, dentre as alternativas, desenvolveu-se algumas atividades matemáticas articuladas por um eixo organizador. Esclarece-se que esse eixo organizador foi embasado em alguns pressupostos, a saber: a conexão dos saberes dos aprendizes estabelecendo uma interdiciplinaridade, com o intuito de valorizar os seus conhecimentos prévios; a organização do espaço e tempo para o desenvolvimento das atividades a partir de oficinas pedagógicas onde se estabelece uma mediação pedagógica entre o professor e os aprendizes; e uma aproximação da dinâmica dos Três Momentos Pedagógicos de Delizoicov e Angotti (1991), para desenvolver as atividades.

Além desses pressupostos, para fins de contextualização, esse estudo explorará a atividade matemática que serviu de eixo. Destaca-se que, o conjunto de todas as atividades formam uma Unidade Didática Interdisciplinar (UDI) explorando, primordialmente, o compartilhamento de saberes e aprofundamento das reflexões sobre os limites e possibilidades destas atividades com o objetivo de aprimorar o processo de ensino e de aprendizagem.

Esclarece-se que o presente estudo foi documentado no decorrer das atividades na forma de imagens e relatos que foram apontados pelo professor do curso com a intenção de também aprimorar a sua prática docente. Ressalta-se que, durante o processo foram preservados no anonimato todos os nomes, locais e datas, respeitando a individualidade dos aprendizes.

\section{CONTEXTO DA PROPOSTA}

O curso de extensão em questão foi organizado por uma instituição de Ensino Superior do Vale do Taquari-RS, com o intuito de auxiliar jovens com necessidades educacionais especiais a ingressarem no mercado de trabalho. 
Tratava-se de um curso distribuído em 3 módulos envolvendo várias áreas, como por exemplo, Língua Portuguesa, Informática e Matemática, sendo que cada área possuía um professor específico.

$\mathrm{Na}$ área das Ciências Exatas destacaram-se os módulos de Matemática, Matemática Financeira e Matemática para Consumo. Cada um desses módulos foi ministrado em semestre distinto. Além disso, cada encontro perdurou por cerca de 4 horas, totalizando 20 horas de carga horária por módulo.

A atividade que será abordada na sequência, foco desse recorte, foi organizada no módulo de Matemática que abordou conteúdos de matemática básica, tais como razão e proporção, grandeza, regra de três, dentre outros. A proposta foi desenvolvida com um grupo de 12 aprendizes com déficit de aprendizagem, deficiências auditivas e motoras. O objetivo do curso de extensão para esse módulo era o de promover, a partir dos conteúdos matemáticos, uma qualificação profissional dos aprendizes, levando em consideração as dimensões ética, cognitiva, social e cultural, buscando o desenvolvimento da autonomia dos aprendizes.

\section{O EIXO ORGANIZADOR}

A noção de eixo organizador já foi explorada em outros momentos pelos autores como uma forma de organizar materiais e atividades em ambientes de oficinas pedagógicas, a saber: Neuenfeldt, 2006; Neuenfeldt e Rodrigues, 2011, dentre outros. Em resumo, trata-se de um elo de ligação entre diversas atividades que levam à concretização de um objetivo, no caso a aprendizagem matemática. Destaca-se que não se trata de um eixo estático, pois pode incorporar os saberes dos aprendizes no decorrer das atividades. Além disso, considerando a dimensões antes esboçadas, desenvolver atividades em equipe se mostrou como primordial, uma vez que os aprendizes estavam sendo preparados para ingressar no mercado de trabalho e necessitariam conviver com seus colegas de trabalho.

Para fins de contextualização, o eixo organizador pode ser um texto, um vídeo ou mesmo uma atividade. Entretanto, alguns elementos foram adotados para caracterizar as ações desenvolvidas na perspectiva dessa proposta, a compartilhar: ocorre sempre num espaço de oficina pedagógica; busca incorporar teoria e prática durante o desenvolvimento das atividades compartilhando 
saberes de forma interdisciplinar; o desenvolvimento das atividades faz uso de uma aproximação dos três momentos pedagógicos de Delizoicov e Angotti (1991); e provoca um reflexão sobre as atividades que são realizadas. No caso dessa proposta, optamos por um eixo organizador na forma de uma atividade de construção, que será apresentada na sequência.

Quanto aos Três Momentos pedagógicos (TMP), de Delizoicov e Angotti (1991), caracterizam-se por uma Problematização Inicial (PI)., No primeiro momento estimula-se os aprendizes mediante um questionamento, para que a partir disso o professor possa acessar algumas ideias prévias, que poderão ser desenvolvidas no decorrer das atividades dos alunos, a respeito do assunto a ser tratado. No segundo momento, também denominado de Organização do Conhecimento (OC), busca-se sistematizar o conhecimento a partir de atividades para dar uma resposta mais adequada ao questionamento inicial. Já no terceiro momento, da Aplicação do Conhecimento (AC), retoma-se as questões iniciais e propõe novos questionamentos, novas situações problemas que possibilitem aos aprendizes a utilização dos conhecimentos que já foram desenvolvidos e ao professor um acompanhamento do processo de ensino e de aprendizagem.

Ressalta-se que no decorrer das atividades forma-se um conjunto, que dá corpo uma Unidade Didática Interdisciplinar (UDI), tendo no seu centro o eixo organizador. A figura a seguir, Figura 1, abaixo ilustra, resumidamente, uma destas organizações:

\section{Figura 1-ELEMENTOS DA UDI}

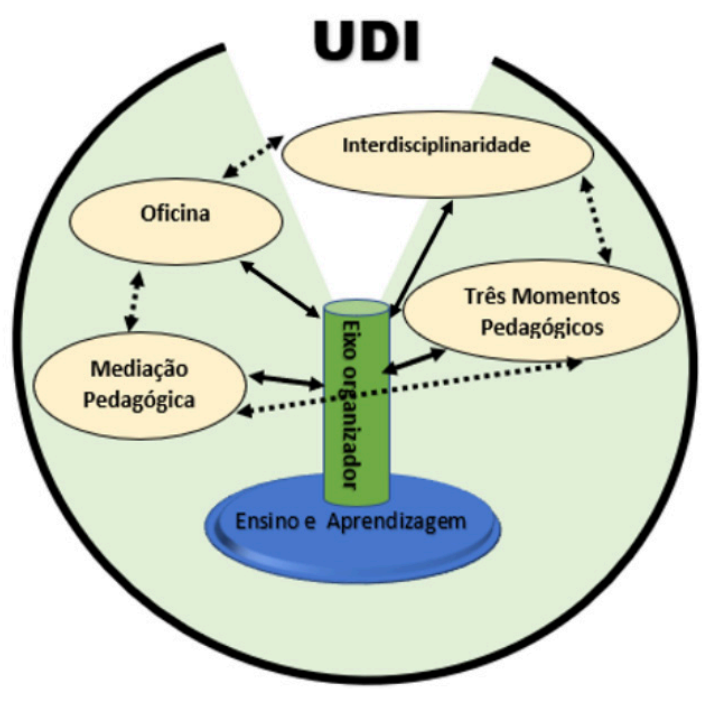

Fonte: DOS AUtORES. 


\section{O OFICINAS PEDAGÓGICAS COMO UM ESPAÇO DE MEDIAÇÃO PEDAGÓGICA}

Tendo em vista que a organização do tempo e do espaço eram primordiais para desenvolver as atividades com o grupo de aprendizes, foi adotado o formato de aulas oficinas. Nesse espaço se explorou o tecer das relações entre os aprendizes durante a aprendizagem de conteúdos matemáticos. Com isso, não se está dizendo que os conteúdos não eram importantes, teoria e prática coexistem, contudo, observou-se que a simples transmissão de conteúdos de modo convencional, com quadro e caneta, não funcionaria, resultando em aprendizagem. Além disso, essa forma de ensinar não atenderia aos objetivos se os aprendizes não conseguissem estabelecer relações sociais com o grupo e com o ambiente de trabalho para os quais estavam designados. Os conteúdos matemáticos eram básicos e deveriam produzir algum significado para a aprendizagem dos aprendizes, pois a pergunta mais frequente era: "Preciso saber disso para quê?"

Por isso, o formato de aulas no sistema de oficinas se mostrou adequado, nas quais se entendeu, conforme Vieira e Volquind (2002), a oficina como uma modalidade de ação. Nesse sentido, nesse espaço, procurou-se combinar o trabalho individual e a tarefa socializada, proporcionando reflexões intra e interpessoais. Cuberes (1989, p. 3), corrobora com a intenção da proposta uma vez que descreve a oficina como "um tempo e um espaço para aprendizagem; um processo de transformação recíproca entre o sujeito e o objeto, um caminho com alternativas, com equilibrações que nos aproximam progressivamente do objeto a conhecer".

Além disso, as atividades propostas nesse espaço necessitavam ser atrativas para os aprendizes. Elas deveriam provocar os aprendizes, incitar a vontade de querer aprender. De acordo com Vieira e Volquind (p. 12, 2002), a oficina pode e deve ser caracterizada como uma realidade que integra três instâncias, o pensar, o sentir e o agir. E, nessa busca pela melhor forma de ensinar e aprender, deve haver espaço para a flexibilidade entre o planejado e a prática.

Para que as atividades alcançassem seus objetivos foi necessário estabelecer uma relação de respeito e troca de saberes entre o professor e os aprendizes. $\mathrm{O}$ professor passou a mediar a aprendizagem buscando estratégias de ensino para explorar as potencialidades de cada um dos aprendizes. A mediação pedagógica tem a ver com a atitude do professor que, para que os aprendizes atinjam os seus objetivos se coloca como " [...] um facilitador, incentivador ou 
motivador da aprendizagem, que se apresenta com a disposição de ser uma ponte entre o aprendiz e sua aprendizagem - não uma ponte estática, mas uma ponte 'rolante'[...]"(MASETTO, 2000, p. 144-145).

Além disso, durante a organização prévia das oficinas estipula-se metas, estabelece-se roteiros, mas quando os aprendizes trazem algo que possa ser utilizado, aproveita-se a oportunidade. Portanto, não existe um caminho único, mas caminhos, com margens para várias possibilidades. Segundo Lespada (1988, p. 21), a oficina "é uma forma, um caminho, um guia flexível, enriquecedora para a pessoa e para o grupo, fundamentada no aprender fazendo com prazer e na ativação do pensamento por própria convicção, necessidade e elaboração."

Concorda-se com Vieira e Volquind (2002, p. 13) ao destacar que "não são os materiais que farão o ensino se tornar mais qualificado, mas sim o uso que o professor fará deste material na oficina", pois é o professor o organizador desses materiais. Por isso, o professor necessita conhecer bem os seus aprendizes para melhor explorar as potencialidades dos mesmos naquele espaço. Em uma oficina, os recursos materiais também devem ser articulados de modo a provocar reflexões e uma releitura dos mesmos. Cada turma será única e, portanto, as ações devem ser pensadas de acordo com a realidade das mesmas. Por exemplo, para aprendizes com dificuldades motoras pode se tornar estressante apresentar uma dobradura ou uma atividade de corte com tesoura.

\section{O INTERDISCIPLINARIDADE}

Quanto à interdisciplinaridade, ela surge como possibilidade de diálogo entre as áreas do conhecimento, pois havia noções de matemática, de artes, de história, de geografia, dentre outras, que transpareciam nas atividades, mas as experiências de vida dos participantes também traziam informações e conhecimentos, cada um dos participantes trazia consigo saberes que poderiam se adequar à várias disciplinas e que se entrelaçam de forma interdisciplinar.

Assim, a interdisciplinaridade surge nesse contexto com o propósito de dar importância aos saberes e conectar com a realidade desses aprendizes, contribuindo para a produção de significados do que é ensinado e aprendido. A preocupação com um ensino que não seja fragmentado não é algo recente, por isso busca-se alternativas que possam solucionar ou amenizar o problema. A esse 
respeito, Japiassu, em 1976, já apontava que a interdisciplinaridade está atrelada "[...]às dificuldades com que atualmente se debatem as instituições de ensino, com seus procedimentos pedagógicos, bem como aos problemas com que se defrontam os empreendimentos visando ao controle do futuro da sociedade, com seus empreendimentos de planificação" (JAPIASSU, 1976, p. 42-43).

Durante o desenvolvimento da proposta observou-se uma interdisciplinaridade para além dos conteúdos distribuídos em ementas, uma interdisciplinaridade que surge a partir da troca de saberes dos aprendizes e do professor, para tentar compreender conceitos matemáticos, ou seja, aproveitando-se dos saberes do grupo. Assim, recorreu-se a autores como Japiassu (1976), Fazenda (1991;199); Paviani e Botomé (1993), Jantsch e Bianchetti (1995) e Vasconcelos (2002), Neuenfeldt (2006), dentre outros, para clarificar a noção de interdisciplinaridade, suas possibilidades de uso e seus limites.

A partir dessas leituras percebeu-se que não existe um significado único para o termo interdisciplinaridade, possuindo diferentes interpretações, porém observou-se que todas elas almejam implicitamente uma nova postura diante do conhecimento, com uma reestruturação diante dos saberes, com limites menos precisos, mas com uma intensidade maior na produção de significados do que está sendo aprendido ou ensinado.

Fazenda (1995, p.18), afirma que: "o projeto interdisciplinar surge às vezes de um (aquele que já possuía em si a atitude interdisciplinar) e se contamina para outros e para o grupo". Ou seja, mesmo quando há um coletivo, cada indivíduo possui inúmeros saberes, assim, o interdisciplinar pode surgir a partir desse indivíduo que compartilha com os demais.

Segundo a mesma autora, percebe-se que a interdisciplinaridade não é algo estático, pois o que:

(...) caracteriza a atitude interdisciplinar é a ousadia da busca, da pesquisa, é a transformação da insegurança num exercício do pensar, num construir. A solidão dessa insegurança individual que caracteriza o pensar interdisciplinar pode diluir-se na troca, no diálogo, no aceitar o pensar do outro. Exige a passagem da subjetividade para a intersubjetividade. (FAZENDA, 1995, p. 18)

Percebe-se que nesse coletivo há uma diversidade de saberes. Conforme Lück (1994), através da interdisciplinaridade:

Busca-se estabelecer o sentido de unidade na diversidade, mediante uma visão de conjunto, que permita ao homem fazer sentido dos conhecimentos e informações dissociados e até 
mesmo antagônicos que vem recebendo, de tal modo que possa reencontrar a identidade do saber na multiplicidade de conhecimentos (LÜCK, 1994, p. 59).

Já para Japiassu (1976, p. 43-44), a interdisciplinaridade pode surgir a partir de duas preocupações fundamentais, a primeira delas relativa "às estruturas e aos mecanismos comuns às diferentes disciplinas científicas" que ingressam num processo de interação ou de colaboração; e a segunda delas diz respeito "aos possíveis métodos comuns a serem instaurados para as disciplinas cooperantes" (JAPIASSU, 1976, p.43-44).

Assim, percebe-se que a partir da interdisciplinaridade há uma intenção de organizar um processo para superar a dissociação das disciplinas que, segundo Lück (1994, p. 49), constituem-se “(...) numa visão limitada para orientar a compreensão da realidade complexa dos tempos modernos e da atuação em seu contexto".

No entanto, deve-se ter o cuidado de não confundir a interdisciplinaridade como uma mistura de conteúdos, mas pensar nela como um corpo estruturado com propostas de trabalho bem definidas, para que isso não interfira na aprendizagem (ETGES, 1995).

\section{OBJETIVO E METODOLOGIA DA PROPOSTA}

O objetivo da proposta foi desenvolver o senso de equipe a partir da organização de atividades matemáticas em torno de um eixo organizador. Metodologicamente, a proposta se configurou como uma pesquisa-ação, na qual os aprendizes e o professor permutaram saberes durante as atividades que foram desenvolvidas.

Segundo Thiollent (2003, p. 14), a pesquisa-ação é uma forma de pesquisa com empirismo "[...] que é concebida e realizada em estreita associação com uma ação ou com a resolução de um problema coletivo e no qual os pesquisadores e participantes representativos da situação ou do problema estão envolvidos de modo cooperativo ou participativo". Além disso, de acordo com Thiollent (2006, p. 156), a pesquisa-ação é "realizada em um espaço de interlocução onde os autores implicados participaram na resolução dos problemas, com conhecimentos diferenciados, propondo soluções e aprendendo na ação". O que reforça a importância do papel do professor como mediador da proposta.

A coleta de dados foi realizada a partir de apontamentos realizados pelo professor em seu diário de bordo. Foram coletadas anotações, fotos e depoimentos, 
e esse material permanece em sigilo, preservando o devido anonimato. Além disso, a pesquisa também possui uma abordagem qualitativa, pois procurou privilegiar, a compreensão dos comportamentos dos aprendizes (BOGDAN; BIKLEN, 1994).

\section{ATIVIDADES DESENVOLVIDAS}

As atividades escolhidas para representarem o eixo organizador foram organizadas a partir de alguns momentos, a saber:

\section{Primeiro momento}

A primeira fase teve início com um vídeo que foi assistido com os aprendizes. O vídeo tratava de construções, prédios, pontes e casas. Os aprendizes assistiram atentos e durante a sessão emitiram comentários a respeito. Em seguida, foi lançado um questionamento: "O que precisaríamos saber para construir uma daquelas construções?” As respostas foram coletadas e surgiram dentre elas, ser pedreiro, ser engenheiro, saber matemática.

$\mathrm{Na}$ sequência foi solicitado aos estudantes que fechassem os olhos e tentassem se recordar de suas casas. Após alguns instantes, eles abriram os olhos e enumeraram numa folha, por escrito, tudo o que se lembravam de suas respectivas casas, por exemplo: número de quartos, quais as mobílias e os eletrodomésticos que possuíam. Esse primeiro momento perdurou por uma tarde.

\section{Segundo momento}

Inicialmente foi apresentado aos aprendizes alguns materiais, como por exemplo, régua, calculadora e transferidor. Foi discutido para que cada um deles servia. Em seguida, de posse desses materiais eles rascunharam a planta baixa de suas casas, colocando inclusive o mobiliário. Também foi solicitado aos aprendizes que colocassem as tomadas elétricas e interruptores.

Esse segundo momento perdurou por mais uma tarde e durante a execução da planta baixa foi trabalhado unidades de medida, noção de perímetro e área, sendo que todas as medidas eram aferidas com a régua, apontadas e revisadas com o uso da calculadora. Os aprendizes compartilhavam as respostas e auxiliavam os colegas a compreender os respectivos projetos. 


\section{Terceiro momento}

Para o terceiro momento os aprendizes foram organizados em 4 grupos de 3 integrantes cada. Em seguida, foi entregue a cada grupo uma foto da Torre Eiffel, juntamente com uma bandeja contendo 30 palitos de churrasco, 01 tesoura, 01 metro de fita adesiva, 60 centímetros de linha e uma trena. A partir disso foi lançado o seguinte desafio: Utilizando todo o material que foi entregue o grupo deve construir uma réplica da torre com a maior altura possível. Algumas observações são pertinentes: não deveria sobrar material; a torre deveria ser uma releitura da Torre Eiffel; a torre deveria ser resistente a ponto de ser carregada de sobre uma superfície de um lado a outro da sala de aula.

Como resultado foram construídas 04 torres de diferentes maneiras, conforme exemplos representados da Figuras 2 e 3 :

\section{Figuras 2 E 3 -EXEMPLOS DE TORRES}
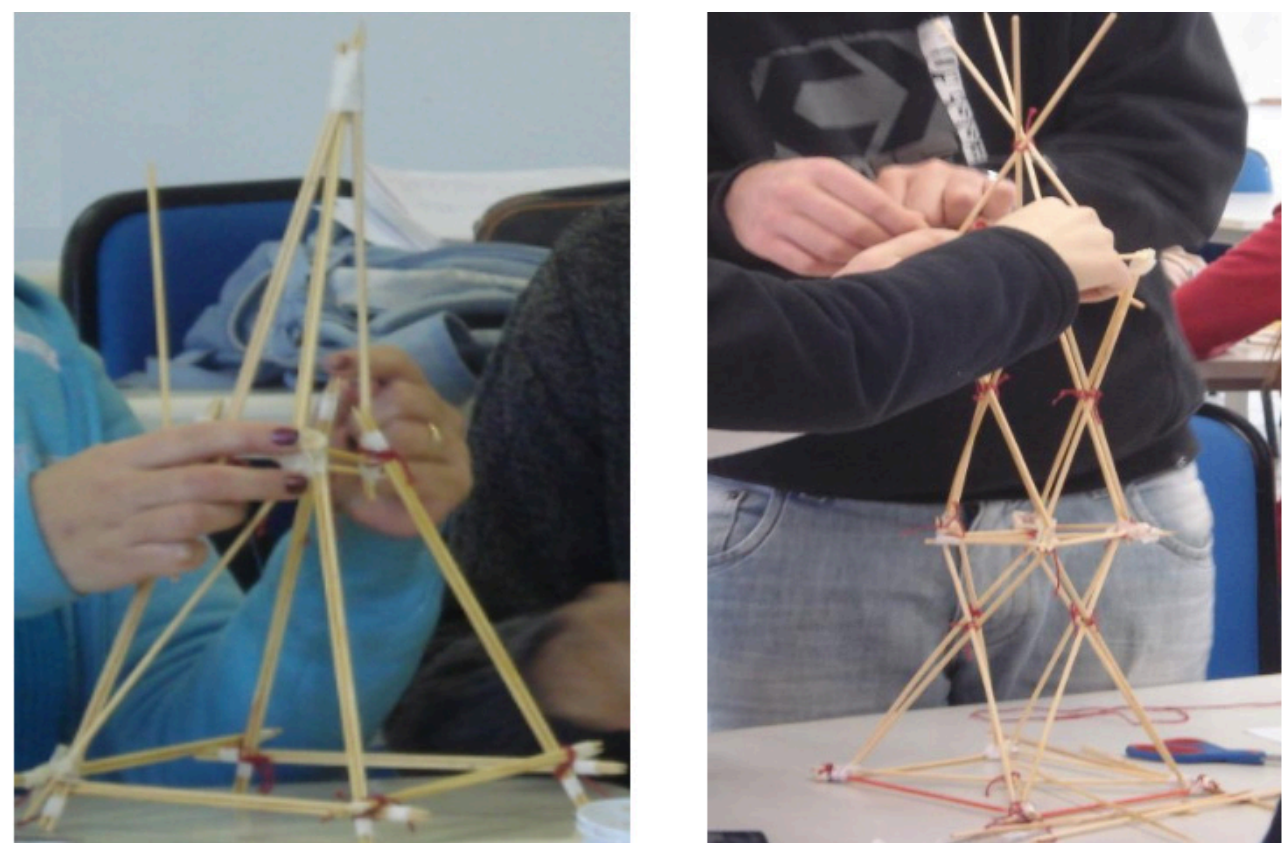

Fonte: DOS Autores.

Durante duas horas os aprendizes trabalharam sem parar. Alguns fizeram esboços em papel outros começaram a construir a torre pela parte mais alta, outros pela base. A régua, a trena e o transferidor eram utilizados com frequência. Contudo, o que mais chamou atenção foram os papeis que eles tomaram durante a atividade. Eles se organizaram de modo que um cortava a fita, 
outro a linha, em duplas amarravam porque descobriram que precisavam do outro, para atar um nó ou sustentar parte da torre, era necessário mais do que duas mãos, assim eles acabaram se ajudando, enfim, trabalharam em equipe.

Ao final da atividade, com todas as torres prontas o grupo se reuniu, colocou-as em exposição e comparou como os colegas haviam realizado as construções. Nesse momento, eles também aproveitaram para mensurar a altura de cada uma das torres.

\section{CONSIDERAÇÕES A PARTIR DA ANÁLISE DAS ATIVIDADES REALIZADAS}

A partir dessa proposta, algumas considerações puderam ser realizadas observando o papel do professor, dos aprendizes e das atividades realizadas.

A primeira delas diz respeito aos sentimentos que afloraram nos aprendizes durante as atividades. $\mathrm{O}$ espaço das oficinas permitiu que eles compartilhassem sonhos, metas. O fato de frequentarem o campus de uma universidade, durante o curso de extensão, já os fez se sentirem parte de algo. Não há como esquecer que, acima de tudo eram jovens, que participavam de redes sociais, possuíam grupos de amigos, preocupavam-se com as roupas que vestiam, com as músicas que escutam, com os lugares de diversão que frequentavam, e no decorrer das aulas percebeu-se que eles estavam procurando se sentir úteis, e esse sentimento vinha com a possibilidade de ter um emprego.

O segundo ponto a destacar foi trabalho em equipe, ele aflorou no decorrer das atividades sem que houvesse uma imposição. A execução das atividades foi discutida nos grupos e os papeis foram assumidos naturalmente. Eles testavam os materiais e num processo de acerto e erros se envolviam na proposta e tentavam encontrar respostas para os problemas. Não se percebeu excluídos, aqueles com dificuldades motoras também ajudavam, mesmo que fosse para alcançar um material ou sugerir alguma mudança. Foi interessante perceber que as dificuldades de um eram suplantadas pelas potencialidades do outro.

Quanto aos conteúdos matemáticos, terceiro ponto, preocupação constante de um ensino convencional, ora ensinados a partir de transmissão, nesse espaço foram utilizados pelos aprendizes com naturalidade. Utilizaram a régua para medir a altura da torre, o transferidor para ver o ângulo de inclinação e assim 
por diante. A matemática foi aprendida enquanto os aprendizes compartilhavam seus saberes com os colegas.

Enfim, como quarto ponto destaca-se o papel do professor, que nesse processo, atuou como um mediador, interferindo menos possível na criação dos aprendizes. Por vezes, atuou, como ouvinte dos aprendizes, apenas dando indicações que ali estavam os conteúdos matemáticos, e assim, essa mediação pedagógica perdurou por todo o processo. Coube a ele pesquisar e desenvolver estratégias que contemplassem a individualidade e o grupo, explorando as respectivas potencialidades. Isso só foi possível porque o espaço das oficinas permitiu o compartilhamento, a flexibilidade e reflexão sobre as atividades que foram desenvolvidas.

\section{REFERÊNCIAS}

BOGDAN, R. C.; BIKLEN, S. K. A investigação qualitativa em educação. 1. ed. Porto/ Portugal: Porto, 1994. (Coleção Ciências da Educação).

CUBERES, M. T. G. Ell taller dos talleres. Buenos Aires: Estrada, 1989.

DELIZOICOV, D., ANGOTTI, J. A. P. Metodologia do Ensino de Ciências. São Paulo: Cortez, 1991.

ETGES, N. J. Ciência, Interdisciplinaridade e Educação. In: JANTSCH, A. P., BIANCHETTI, L. Interdisciplinaridade: para além da filosofia do sujeito. Petrópolis, RJ: Vozes, 2002. p. 51-84.

FAZENDA, I. C. Interdisciplinaridade: Um projeto em parceria. 5. ed. São Paulo: Loyola, 2002. v. 13. (Coleção Educar).

. (Org.) Práticas interdisciplinares na escola. 10. ed. São Paulo: Cortez, 1995.

JANTSCH, A. P., BIANCHETTI, L. (Orgs). Interdisciplinaridade: para além da filosofia do sujeito. 6. Ed. Petrópolis, RJ: Vozes, 1995.

JAPIASSU, H. Interdisciplinaridade e Patologia do Saber. Rio de janeiro: Imago, 1976.

LESPADA, J. C. Aprender haciendo: los talleres em la escula. Buenos Aires: Humanitas, 1988.

LÜCK, H. Pedagogia interdisciplinar: fundamentos teórico-metodológicos. Petrópolis, RJ: Vozes, 1994.

MASETTO, M. T. Mediação Pedagógica e o uso da tecnologia. In: MORAN, J. M.; MASETTO, M. T.; BEHRENS, M. A. Novas Tecnologias e mediação Pedagógica. 1. ed. Campinas: Papirus, 2000. p. 133-173 
MORAN, J. M. Ensino e aprendizagem inovadores com apoio de tecnologias. In: MORAN, J. M.; MASETTO, M. T.; BEHRENS, M. A. Novas Tecnologias e mediação Pedagógica. 1.ed. Campinas: Papirus, 2015a. p.141-181.

NEUENFELDT, A. E. Matemática e literatura infantil: Sobre os limites e possibilidades de um desenho curricular interdisciplinar. 2006. 195f. Dissertação (Mestrado em Educação) - Universidade Federal de Santa Maria, Santa Maria, 2006.

NEUENFELDT, A. E. RODRIGUES, A. W. L. Interdisciplinaridade na escola: uma possibilidade a partir do texto como eixo organizador de unidades didáticas interdisciplinares. Revista Ibero-Americana de Educação, vol. 54, n. 5, 2011. Disponível em: <http://www. rieoei.org/index.php>. Acesso em: 10 maio 2019.

PAVIANI, J.; BOTOMÉ, S. P. Interdisciplinaridade: disfunções conceituais e enganos acadêmicos. Caxias do Sul, RS: EDUCS, 1993.

THIOLLENT, M. Metodologia da pesquisa-ação. 12. ed. São Paulo: Cortez, 2003. (Coleção temas básicos de pesquisa-ação).

A inserção da pesquisa-ação no contexto da extensão universitária. In: BRANDÃO, C. R.; STRECK, D. R. (Orgs.). Pesquisa participante: o saber da partilha. 2. ed. Aparecida, SP: Ideias Et. Letras, 2006. p.151-165.

VASCONCELOS, E. M. Complexidade e pesquisa interdisciplinar: epistemologia e metodologia operativa. Petrópolis, RJ: Vozes, 2002. 